\title{
ANALISIS PEMBERIAN BANTUAN SOSIAL PROGRAM KELUARGA HARAPAN TERHADAP PRESTASI BELAJAR ANAK DI KECAMATAN SEPAUK
}

\author{
Suparno \\ STKIP Persada Khatulistiwa Sintang, Pendidikan Pancasila dan Kewarganegaraan,Sintang \\ Email : Suparnowae4@gmail.com
}

\begin{abstract}
The problem in this research is Ho the granting of social assistance Program Family child learning accomplishments against Expectations in district Sepauk. Research objectives to describe the granting of social assistance Program Family child learning accomplishments against Expectations in district Sepauk. The method used in this research is qualitative descriptive and form case study research. The data collection technique using observation, interviews, and documentation.The results research showed that: 1) impact of the provision social support Family Hope Program (FHP) can be felt by community, beneficiaries can send their children to school and receive a proper education, 2) Achievements to learn his son increases seen from the achievements the present local, national and international, 3) community response to implementation Family Hope Program very positive because this help can help Very Poor Family in sending their children to school.
\end{abstract}

Keywords: Family Hope Program, Learning Achievements.

ISSN: $2540-8038$ 


\begin{abstract}
Abstrak
Masalah dalam penelitian ini adalah Bagaimanakah pemberian bantuan sosial Program Keluarga Harapan terhadap prestasi belajar anak di Kecamatan Sepauk. Tujuan penelitian untuk mendeskripsikan pemberian bantuan sosial Program Keluarga Harapan terhadap prestasi belajar anak di Kecamatan Sepauk. Metode penelitian yang digunakan dalam penelitian ini adalah kualitatif deskriptif dan bentuk penelitiannya Studi Kasus.Teknik pengumpulan data menggunakan teknik observasi, wawancara, dan studi dokumentasi. Hasil penelitian menunjukkan bahwa: 1) dampak pemberian bantuan sosial Program Keluarga Harapan dapat dirasakan masyarakat, para penerima bantuan dapat menyekolahkan anak-anaknya dan mendapatkan pendidikan yang layak, 2) Prestasi belajar anaknya meningkat dilihat dari prestasi yang diperoleh ditngkat lokal, nasional dan internasional, 3) respon masyarakat terhadap pelaksanaan Program Keluarga Harapan sangat positif karena bantuan ini dapat membantu Keluarga Sangat Miskin dalam menyekolahkan anakanaknya.
\end{abstract}

Kata Kunci: Program Keluarga Harapan, Prestasi Belajar.

ISSN: $2540-8038$ 


\section{A. Pendahuluan}

Isu mengenai kemiskinan ternyata saat sekarang ini telah terbukti, bahwa negara Indonesia terkait angka kemiskinan telah tinggi hal ini terbukti bahwa banyak masyarakat miskin yang tersebar diseluruh tempat diwilayah Indonesia ini. Masyarakat Kalimantan Barat, khususnya Kabupaten Sintang terdapat masyarakat miskin yang jumlahnya tinggi, hal ini dapat dilihat bahwa banyaknya anak putus sekolah dan tidak dapat masuk sekolah sampai perguruan tinggi yang disebabkan oleh adanya ketidak mampuan biaya untuk sekolahnya.

Terkait tingginya angka kemiskinan sebagai mana terlansir dalam data BPS bahwa angka kemiskinan di Indonesia mengalami kenaikan dari tahun ke tahun. Badan Pusat Statistik (BPS) menginformasikan, jumlah penduduk miskin (penduduk dengan pengeluaran per kapita per bulan di bawah Garis Kemiskinan) di Indonesia per September 2016 mencapai 27,76 juta orang $(10,70$ persen) (Badan Pusat Statistik (BPS).2016. Jumlah Pendduduk
Miskin.terdapat di laman http://setkab.go.id/bps-perseptember-2016-jumlah-pendudukmiskin-indonesia-bekurang-025juta/). Data ini membuktikan bahwa Tingkat kemiskinan di Indonesia tinggi, dengan demikian perlu adanya upaya penanganan yang serius terutama bagi pemerintah yang memiliki tugas dan wewenang untuk mensejahterakan rakyat. Menyikapi masalah ini pemerintah mulai mengupayakan berbagai cara penanggulangan melalui berbagai pendekatan yang relevan.

Upaya yang dilakukan dalam pengentasan kemiskinan yaitu melalui Program Dinas Sosial berupa Pendamping Keluarga Harapan (PKH). Program ini merupakan bentuk wujud berupa bantuan sosial. Menurut Suharto (2007 : 88) "bantuan sosial merupakan salah satu bentuk program jaminan sosial (social security) yang berupa tunjangan uang, barang, atau pelayanan kesejahteraan yang umumnya diberikan kepada populasi paling rentan yang tidak memiliki penghasilan yang layak bagi kemanusiaan". Pelayanan sosial, 
dana BOS, Jamkesmas, PNPMMandiri, Raskin, Bantuan Langsung Tunai, Program Keluarga Harapan (PKH) dan lain-lain dikategorikan sebagai bantuan sosial.

Tim Direktorat Jaminan Sosial (2015: 12) sejak tahun 2007 Pemerintah Indonesia telahmelaksanakan Program Bantuan Tunai Bersyarat (BTB)yang dikenal dengan nama Program KeluargaHarapan (PKH) sebagai salah satu tahapan menuju sistem perlindungan sosial. Program BantuanTunai Bersyarat atau disebut Conditional Cash Transfers(CCT), telah dilaksanakan di beberapa negara dan cukupberhasil dalam menanggulangi kemiskinan yang dihadapinegara-negara yang melaksanakan CCT. Program Keluarga Harapan (PKH) merupakan program lintas Kementrian dan Lembaga, karena aktor utamanya adalah dari Badan Perencanaan Pembangunan Nasional, Departemen Sosial, Departemen Kesehatan, Departemen Pendidikan Nasional, Departemen Agama, Departemen Komunikasi dan Informatika, dan
Badan Pusat Statistik (Virgoreta, 2015: 2).

Bantuan yang telah diterima menjadikan anak dapat terbantu biaya sekolahnya. Dengan demikian maka anak akan menjadi semangat dalam sekolah. Dengan semangat yang tinggi maka akan menjadikan berprestasi. Murphy (2009: 22) menyebutkan bahwa faktor yang mempengaruhi prestasi belajar yaitu: "the extent to which educators, students, and the total educational environtment reflect culture competence significantly affects the nature and type of schooling, conditions of learning, as well as learning outcomes". Pendapat tersebut mengandung makna bahwa faktor-faktor yang berpengaruh terhadap prestasi belajar diantaranya adalah pendidik, siswa, dan lingkungan pendidikan yang mencerminkan budaya kompetensi. Faktor pendidik dapat dilihat dari kinerja guru, faktor siswa dapat dilihat dari motivasi berprestasi dan disiplin belajar, lingkungan dapat dilihat yaitu kondisi keluarga yang memiliki penghasilan yang cukup, 
pelaksanaan prakerin serta dukungan orang tua.

Amrai, K., Motlagh, S. E., Zalani, H. A., \& Parhon, H. (2011: 123) mengungkapkan bahwa "students academic achievement requires coordination and interaction between different aspects of motivation". Hal tersebut mengandung makna bahwa prestasi belajar akademik siswa merupakan hasil dari koordinasi dan interaksi antara aspek-aspek motivasi yang berbeda. Keseluruhan aspek motivasi harus ditingkatkan secara menyeluruh untuk dapat mendukung peningkatan prestasi belajar siswa.

Berdasarkan pemaparan yang sudah diuraikan diatas, maka peneliti tertarik mengangkat judul "analisis pemberian bantuan sosial program keluarga harapan terhadap prestasi belajar anak di Kecamatan Sepauk".

\section{B. Metode}

Metode yang digunakan dalam penelitian ini adalah metode kualitatif dengan bentuk penelitian studi kasus. Yin (2014, hlm. 1) studi kasus adalah salah satu metode penelitian ilmu-ilmu sosial. Bogdan \& Biklen (1982: hlm. 58) mengatakan: "A case study is a detailed examination of one setting or one single subject or one single depository of document or one particular event." Selanjutnya, Bogdan \& Biklen (1982, hlm. 59) menggambarkan rancangan umum dari sebuah studi kasus itu sebagai berikut: (1) peneliti mencari tempat dan orang yang akan dijadikan sebagai subjek atau sumber data, (2) menemukan lokasi yang diinginkan untuk dikaji kemudian mencoba mempertimbangkan kelayakan tempat tersebut atau sumber data untuk mencapai tujuannya, (3) mencari kunci-kunci tentang bagaimana ia dapat melangkah dan apa yang semestinya dilakukan, (4) memulai mengumpulkan data, mereviu, dan mengeksplorasinya, (5) membuat keputusan tentang arah yang akan dituju dengan penelitiannya, (6) membuat keputusan tentang bagaimana mengatur waktu, siapa yang akan diinterviuw dan apa yang akan digali secara mendalam, (7) memodifikasi desain secara terus menerus dan memilih prosedur yang lebih sesuai dengan topic kaian, (8) membuat 
keputusan berkenaan dengan aspek apa di antara setting, subjek, atau sumber data yang akan dikaji, dan (9) mengembangkan fokus.

Metode studi kasus proses pengumpulan data dan kegiatan penelitian akan mempersempit wilayah, subjek, bahan, topik, dan tema. Dari permulaan pencarian yang luas, peneliti bergerak menuju pengumpulan data dan analisis yang lebih terarah. Dalam penelitian ini kasus yang dikaji adalah pemberian bantuan PKH terhadap prestasi belajar siswa.

\section{Pembahasan Dan Hasil}

1. Pemberian Bantuan Sosial Program Keluarga Harapan Pada Keluarga Sangat Miskin (KSM) di Kabupaten Sintang

Berdasarkan hasil penelitian yang dilakukan di Kecamatan Sepauk bahwa bantuan sosial Program Keluarga Harapan ini sudah terlaksana dengan baik, walaupun masih ada masyarakat yang belum terjangkau karena wilayah yang jauh dan infrastruktur jalan yang membuat petugas susah untuk menjangkau wilayah tersebut. Program-program pemerintah seperti Program Keluarga Harapan (PKH) ini sangat dibutuhkan oleh masyarakat yang kurang mampu agar dapat meningkatkan kualitas pendidikan suatu Negara. Selama penelitian dilapangan peneliti menemukan bahwa bantuan sosial ini memberikan dampak yang positif terhadap penerima, karena para penerima bantuan dapat menyekolahkan anak-anaknya dan belum ada menemukan anak putus sekolah setelah menerima bantuan sosial Program Keluarga Harapan (PKH).

2. Prestasi Belajar Anak Setelah Pemberian Bantuan Sosial Program Keluarga Harapan (PKH). 
Terdapat banyak anak yang berprestasi baik dibidang akademik maupun non akademik. Terdata 59 anak yang berprestasi baik ditingkat lokal, nasional maupun internasional. Satu orang anak KPM yang berprestasi ditingkat internasional atas nama Fitri Rini Ariesti anak KPM ibu atas nama Wihelmina Runan dengan prestasi diterima di University Science and Technology Of China (USTC), jurusan Public Administration melalui jalur beasiswa Chinese Goverment Scholarship (CGS). Delapan orang anak KPM berprestasi ditingkat nasional 8 orang, yang terdiri dari prestasi dibidang pendidikan dan seni, dan 50 orang yang berprestasi ditingkat lokal, seperti juara kelas, juara perlombaan pada tingkal lokal sekolah, tingkat kecamatan, kabupaten dan provinsi. Ini menunjukkan bahwa anak-anak KPM PKH memiliki motivasi dan prestasi yang baik dalam belajar.

3. Respon Masyarakat Terhadap Pelaksanaan Program Keluarga Harapan (PKH)

Pelaksanaan Program Keluarga Harapan (PKH) sudah tepat sasaran dan telah efektif dilaksanakan.

Sebagaimana

Berdasarkan

wawancara dan observasi dilapangan bahwa masyarakat menanggapi pelaksanaan Program Keluarga Harapan (PKH) sangat positif dimana ketika ada pertemuan kelompok para penerima bantuan antusias untuk menghadiri pertemuan tersebut. Sikap positif masyarkat ini terlihat pada saat pertemuan kelompok, ketika tidak memahami apa yang disampaikan oleh pendamping maka penerima bantuan dengan antusias bertanya sehingga tidak dapat meminimalisir kasalahan yang kemungkinan terjadi. Pertemuan kelompok dilakukan secara rutin sesuai arahan dari pendamping kecamatan.

Anak penerima bantuan juga memberikan respon yang positif dengan Program Keluarga Harapan (PKH). Respon positif tersebut dilihat dari antusias anak rajin bersekolah, memiliki prestasi yang baik dan mengikuti kegiatankegiatan disekolah. Berdasarkan wawancara dan observasi diketahui bahwa motivasi belajar anak meningkat setelah menerima bantuan 
Program Keluarga Harapan (PKH), karena bantuan ini digunakan secara efektif untuk memenuhi sarana dan prasarana yang dibutuhkan untuk belajar. Adapun kemajuan motivasi belajar anak penerima dapat dilihat dari rekapitulasi hasil nilai raport.

Program Keluarga Harapan (PKH) dapat membantu penerima bantuan yang awalnya mengalami kesulitan untuk menyekolahkan anak setelah menerima bantuan dapat memenuhi semua sarana dan prasarana anaknya untuk bersekolah dan belajar. Program ini membuat masyarakat menyadari bahwa pendidikan itu penting, dan membuat lebih berani berkomunikasi dan menyampaikan pendapat.

\section{Simpulan}

$$
\begin{aligned}
& \text { Berdasarkan dari hasil } \\
& \text { pelaksanaan penelitian yang telah } \\
& \text { lakukan, dapat disimpulkan sebagai } \\
& \text { berikut pemberian bantuan sosial } \\
& \text { Program Keluarga Harapan (PKH) } \\
& \text { pada Keluarga Sangat Miskin (PKH), } \\
& \text { berdasarkan hasil penelitian bantuan } \\
& \text { sosial Program Keluarga Harapan } \\
& \text { (PKH) memberikan dampak yang } \\
& \text { positif. Dengan adanya bantuan ini }
\end{aligned}
$$

menjadikan anak berprestasi. Terdata 59 anak yang berprestasi baik ditingkat lokal, nasional maupun internasional. Satu orang anak KPM yang berprestasi ditingkat internasional atas nama Fitri Rini Ariesti anak KPM ibu atas nama Wihelmina Runan dengan prestasi diterima di University Science and Technology Of China (USTC), jurusan Public Administration melalui jalur beasiswa Chinese Goverment Scholarship (CGS). Delapan orang anak KPM berprestasi ditingkat nasional 8 orang, yang terdiri dari prestasi dibidang pendidikan dan seni, dan 50 orang yang berprestasi ditingkat lokal, seperti juara kelas, juara perlombaan pada tingkal lokal sekolah, tingkat kecamatan, kabupaten dan provinsi. Ini menunjukkan bahwa anak-anak KPM PKH memiliki motivasi dan prestasi yang baik dalam belajar.

Selain dari pada itu penelitian ini menunjukan bahwa adanya bantuan ini mendapatkan respon yang positif baik dari keluarga penerima manfaat program $\mathrm{PKH}$ ini maupun anak penerima manfaat yang sedang duduk di bangku sekolah. 


\section{Daftar Pustaka}

Badan Pusat Statistik (BPS).2016. Jumlah Pendduduk Miskin.terdapat di laman http://setkab.go.id/bps-perseptember-2016-jumlahpenduduk-miskin-indonesiabekurang-025-juta/).
Murphy, P.K. (2009). Cultural competence initiative. The Arlington Publics Schools.

Direktorat Jaminan Sosial. 2015. Buku Pedoman Umum PKH. Jakarta: Direktorat Jenderal Perlindungan dan Jaminan SosialKementerian Sosial RI.

Amrai, K., Motlagh, S. E., Zalani, H. A., \& Parhon, H. (2011). The relationship between academic motivation and academic achievement students. Procedia-Social and Behavioral Sciences, 15, 399-402.
Suharto, Edi. (2007). Kebijakan Sosial Sebagai Kebijakan Publik. Bandung: Alfabeta. 